\title{
PERANAN PROGRAM USAHA PENINGKATAN PENDAPATAN KELUARGA SEJAHTERA (UPPKS) TERHADAP KESEJAHTERAAN MASYARAKAT DI KECAMATAN CIASEM, KABUPATEN SUBANG
}

\author{
Dian Hakip Nurdiansyah, Gusganda Suria Manda \\ Faculty of Economic and Business Singaperbangsa Karawang University \\ Jl. H. Ronggo waluyo Teluk Jambe Timur Karawang Barat \\ e- mail : dian.hakipnurdiansyah@staff.unsika.ac.id
}

\begin{abstract}
Globalization has impacted ons the presence of rapid change of social wealth and also higher poverty. This has driven many institutions to reduce the level of poverty. To do so, iti conducted through the implementation of family empowerment program as developed by $B K K B N$ through a program for increasing the income of family welfare (UPPKS). UPPKS has a goal to improve family income and welfare through family planning as their members. This study used quantitative methods design through survey methods. It used survey collected from respondents using questionnaires. The results showed that the implementation of the program in the UPPKS of Ciasem district has proven effectively can increase income rate and family welfare. The program participants use the program as the capital for small industry, Agroindustry and livestock.
\end{abstract}

Keywords : UPPKS program, Family Planning, poverty

\section{Latar Belakang}

Dampak globalisasi yang sampai saat ini terasa adalah adanya sesuatu yang serba cepat dan hampir terjadi disemua aspek kehidupan baik di lingkup lokal, regional, nasional maupun internasional. Perubahan yang terjadi dengan demikian cepatnya ini menyebabkan keharusan agar diadakan perubahan pada hal-hal yang sifatnya mendasar, misalnya tuntutan untuk memenuhi hidup. Akibatnya bagi mereka yang tidak bisa memenuhi kebutuhannya tersebut, seringkali menjadi rentan dan rawan pada kondisi dan situasi yang mengakibatkan penyimpangan atau pelanggaran norma-norma baik hukum, masyarakat/sosial bahkan norma agama.

Kemiskinan menjadi salah satu masalah di Indonesia sejak dulu hingga sekarang apalagi sejak terhampas dengan pukulan krisis ekonomi dan moneter yang terjadi sejak Tahun 1997. Kemiskinan seringkali dipahami sebagai gejala rendahnya tingkat kesejahteraan sematamata kemiskinan merupakan gejala yang bersifat komplek dan multi dimensi. Rendahnya tingkat kehidupan yang sering sebagai alat ukur kemiskinan pada hakekatnya merupakan salah satu mata rantai dari munculnya lingkaran kemiskinan (Arifin, 2012).

Meskipun kemiskinan telah menjadi subyek penelitian ilmiah sejak lama dengan thema atau label yang beraneka ragam, akan tetapi apabila ditelaah lebih lanjut sebagian besar penelitian tentang kemiskinan yang dilakukan secara ilmiah lebih banyak ditekankan pada pemahaman, yaitu aspek "what it is " dari kemiskinan(Pakpahan, 1996). Sedangkan upaya secara komprehensip dalam penanggulangan kemiskinan masih jarang dilakukan meskipun banyak kebijaksanaa dalam 
menanggulangi kemiskinan telah dilaksakan.

Menurut BPS (2015) di ketahui bahwa terdapat 154.161 keluarga pra sejahtera, 136.155 keluarga sejahtera I, 114,929 keluarga sejahtera II, 43.080 keluarga sejahtera III, dan 49.416 keluarga sejahtera III+b di kecamatan ciasem kabupan subang Jawa barat.

BKKBN adalah satu institusi yang bertanggung jawab dalm hal pengendalian jumlah penduduk di Indonesia. Pemberdayaan keluarga di bidang ekonomi merupakan salah satu usaha yang dapt dilakukan untuk dapat menngkatkan potensi keluarga dalam hal kesejahteraan (Elizabeth, 2007). Pelaksanaan program pemberdayaan keluarga telah dikembangkan oleh BKKBN melalui program usaha peningkatan pendapatan keluarga sejahtera (UPPKS).

Program ini dikembangkan lebih luas melalui pendekatan kelompok, dengan anggota yang mayoritasnya adalah ibu ibu akseptor $\mathrm{KB}$ dengan kegiatan yang dikenal sebagai UPPKA (Usaha Peningkatan Pendapatan Keluarga Akseptor). Pada tahun 1990 UPPKA diubah menjadi UPPKS (Usaha Peningkatan Pendapatan Keluarga Sejahtera) untuk mencakup sasaran yang lebih luas yaitu dengan melibatkan Pasangan Usia Subur (PUS) yang belum ber-KB, Keluarga Pra Sejahtera (KPS), Keluarga Sejahtera I (KS I), dan Keluarga lain yang berminat menjadi anggota Kelompok UPPKS.

Berbagai upaya telah dilaksanakan oleh pemerintah untuk meningkatkan kesejahteraan masyarakat, dan sejak tahun 1976 institusi BKKBN telah melakukan kegiatan yang khususnya ditujukan untuk keluarga akseptor $\mathrm{KB}$ agar mereka dapat memperoleh kehidupan yang lebih baik. Melalui program Community incetive project (CIP) yang penggarapannya dilaksanakan melalui pendekatan dan pembangunan desa secara keseluruhan, para keluarga akseptor diberikan berbagai insentif atas prestasi masyarakat pedesaan dalam kesertaan ber - KB.

Program

peningkatan

kesejahteraaan keluarga akan lebih cepat tercapai melalui pemberdayaan perempuan dalam rumah tangga dengan memberikan keterampilan yang produktif dan mengendalikan jumlah anggota keluarga melalui program keluarga berencana. Program UPPKS di kecamatan Ciasem sampai saat ini belum di evaluasi secara mendalam tentang berbagai variable sebagai ukuran keberhasilan program sesuai dengan tujuan sebelumnya. Sehingga penelitian ini kami lakukan agar diperoleh informasi yang baik untuk program kesejahteraan mendatang.

UPPKS diharapkan adanya meningkatkan pendapatan keluarga yang kemudian akan memperbaiki kesejahteraan, baik dari keluarga peserta KB yang bersangkutan maupun dari seluruh anggota kelompoknya. Dengan peningkatan kesejahteraan tersebut, diharapkan kesertaan dan kesinambungan ber-KB secara tidak langsung dapat ditingkatkan.

Berlatar belakang permasalahan tersebut di atas, maka penulis tertarik untuk melakukan penelitian lebih lanjut mengenai evaluasi program UPPKS dengan judul : "Peranan Program Usaha Peningkatan Pendapatan Keluarga Sejahtera (Uppks) Terhadap Kesejahteraan Masyarakat Di Kecamatan Ciasem, Kabupaten Subang".

Berdasarkan latar belakang tersebut, maka dapatlah dirumuskan permasalahan penelitian ini adalah sebagai berikut :Apakah peranan UPPKS di kecamatan ciasem sudah efektif? Apakah UPPKS sudah bisa meningkatkan kesejahteraan masyarakat di kecamatan ciasem? Apakah kegiatan UPPKS di kecamatan ciasem sudah efektif sesuai dengan standar yang telah ditentukan?

Tujuan dalam penelitian ini, antara lain untuk mengetahui seberapa besar peranan UPPKS kepada masyarakat, Untuk mengetahui apakah UPPKS sudah 
memenuhi efektifitas program pemerintah, dan Untuk mengetahui pengelolaan sistem keuangan UPPKS

\section{Tinjauan Pustaka}

\section{Pengertian UPPKS}

\begin{tabular}{lccr}
\multicolumn{2}{c}{ Menurut } & BKKBN & pengertian \\
UPPKS & adalah & UPPKS & merupakan \\
singkatan dari & "Usaha & Peningkatan
\end{tabular} Pendapatan Keluarga Sejahtera" dan merupakan salah satu program dari Badan Koordinasi Keluarga Berencana Nasional (BKKBN) untuk meningkatkan kesejahteraan masyarakat (Heryendi,2013).

UPPKS sendiri mempunyai pengertian sebagai " Sekumpulan keluarga yang saling berinteraksi dan terdiri dari bebagai tahapan keluarga sejahtera, mulai dari keluarga Pra Sejahtera sampai dengan Keluarga Sejahtera III Plus baik yang sudah menjadi akseptor KB, PUS yang belum ber-KB, serta anggota masyarakat yang berminat dalam rangka mewujudkan keluarga kecil bahagia sejahtera, aktif melakukan berbagai kegiatan usaha bersama dalam bidang usaha ekonomi produktif(UEP)."

\section{Program UPPKS}

Program UPPKS terdiri dari sebuah kelompok usaha yang mempunyai struktur kepengurusan pada umumnya seperti ketua, sekretaris dsb. yang minimal meliputi wialayah satu padukuhan atau desa. Walaupun program ini sudah berjalan puluhan tahun dan sempat berganti-ganti nama usaha pemerintah ini masih menemui banyak kendala dan hambatan sehingga banyak kelompok yang bisa dibilang mati atau tidak berjalan sama sekali (Marhaeni, 2007).

Menurut penelitian yang dilakukan oleh BKKBN Kalibawang Jawa Tengah : 2013 menyatakan bahwa Pelaksanaan program UPPKS sebagai upaya peningkatan pendapatan keluarga haruslah digalakkan demi meningkatkan pendapatan guna meningkatkan kesejahteraan keluarga, khususnya keluarga miskin Pra KS dan KS I. oleh karena itu, sangatlah penting bagi masyarakat di suatu daerah memiliki keterampilan, pengetahuan dan pemanfaatan apa yang ada di sekitarnya untuk bisa dijadikan usaha guna meningkatkan pendapatan keluarga.

\section{Fungsi dan Tujuan UPPKS}

Secara umum tujuan UPPKS ialah untuk meningkatkan kegiatan usaha ekonomi produktif dan keterampilan terutama untuk keluarga akseptor keluarga berencana yang tergabung dalam kegiatan kelompok UPPKS. sementara secara spesifik tujuan dibentuknya kelompok UPPKS antara lain: a) meningkatnya jumlah modal usaha dalam pengembangan usaha kegiatan kelompok UPPKS, b) meningkatnya jumlah kelompok UPPKS yang memperoleh modal usaha, c) meningkatnya jumlah anggota kelompok UPPKS yang berusaha, d) meningkatnya kualitas usaha kegiatan kelompok UPPKS, e) meningkatnya kesejahteraan keluarga khususnya keluarga prasejahtera atau keluarga miskin (Ari:2010).

Menurut abdul Munir, (2010) menyebutkan bahwa dalam evaluasi BKKBN menyatakan bahwa setelah melalui berbagai perjuangan untuk membawa keluarga menyadari pentingnya membangun keluarga kecil (yang bertanggung jawab, bahagia dan sejahtera), Badan Koordinasi Keluarga Berencana Nasional tentu perlu melakukan refleksi diri dan bertanya apakah apabila keluarga kecil ini sudah terbentuk, kemudian perjuangan itu berhenti sampai di situ saja. Akan tetapi masyarakat yang kuat, terbentuk dari keluarga sebagai unit terkecil yang maju dan sejahtera.

\section{Indikator Kesejahteraan Masyarakat}

Indikator atau criteria tingkatan kesejahteraan masyarakat menurut BKKN adalah sebagai berikut: 


\section{Dua Keluarga Pra Sejahtera (Sering dikelompokkan sebagai "Sangat Miskin")}

Belum dapat memenuhi salah satu atau lebih indikator yang meliputi :

a. Indikator Ekonomi

1) Makan dua kali atau lebih sehari

2) Memiliki pakaian yang berbeda untuk aktivitas (misalnya di rumah, berkerja,sekolah dan bepergian)

3) Bagian terluas lantai rumah bukan dari tanah.

b. Indikator Non-Ekonomi

1) Melaksanakan ibadah

2) Bila anak sakit dibawa ke sarana kesehatan

\section{Keluarga Sejahtera I (Sering} dikelompokkan sebagai "Miskin")

Adalah keluaraga yang karena alasan ekonomi tidak dapat memenuhi salah satu atau lebih indikator meliputi :

a. Indikator Ekonomi

1) Paling kurang sekali seminggu keluarga makan daging atau ikan atau telor

2) Setahun terakhir seluruh anggota keluarga memperoleh paling kurang satu stel pakaian baru

3) Luas lantai rumah paling kurang $8 \mathrm{~m}$ untuk tiap penghuni

b. Indikator Non-Ekonomi

1) Ibadah teratur

2) Sehat tiga bulan terakhir

3) Punya penghasilan tetap

4) Usia 10-60 tahun dapat baca tulis huruf

5) Usia 6-15 tahun bersekolah

6) Anak lebih dari 2 orang, ber$\mathrm{KB}$

\section{Keluarga Sejahtera II}

Adalah keluaraga yang karena alasan ekonomi tidak dapat memenuhi salah satu atau lebih indikator meliputi :
1) Memiliki tabungan keluarga

2) Makan bersama sambil berkomunikasi

3) Mengikuti kegiatan masyarakat

4) Rekreasi bersama (6 bulan sekali)

5) Meningkatkan pengetahuan agama

6) Memperoleh berita dari surat kabar, radio, TV, dan majalah

7) Menggunakan sarana transporstasi

\section{Keluarga sejahtera III}

Sudah dapat memenuhi beberapa indikator, meliputi:

1) Memiliki tabungan kelurga

2) Makan bersama sambil berkomunikasi

3) Mengikuti kegiatan masyarakat

4) Rekreasi bersama (6 bulan sekali)

5) Meningkatkan pengetahuan agama

6) Memperoleh berita dari surat kabar, radio, TV, dan majalah

7) Menggunakan sarana transporstasi

Belum dapat memenuhi beberapa indikator. meliputi :

1) Aktif memberikan sumbangan material secara teratur

2) Aktif sebagai pengurus organisasi kemasyarakatan.

\section{Keluarga sejahtera III plus} meliputi :

Sudah dapat memenuhi indikator

1) Aktif memberikan sumbangan material secara teratur

2) Sebagi pengurus organisasi Kemasyarakatan.

Ketentuan ketentuan pokok kesejahteraan social berdasarkan Undang0undang nomor 6 tahun 1974 merupakan bentruk kondisi kehidupan dan penghidupan social materi 
meliputi rasa keselamatan dan human capital dapat mendorong peningkatan produktivitas dan pendapatan tenaga kerja serta membantu keluarga miskin keluar dari lingkaran kemiskinan (Niken, 2010)

\section{Desain penelitian}

Desain penelitian ini menggunakan metode kuantitatif, metode survey atau explanatory. Dalam penelitian survey informasi dikumpulkan dari responden dengan menggunakan kuisioner. Data kuantitatif yang berasal dari data sekunder digunakan untuk mendukung analisis penelitian secara keseluruhan sebagai pembuktian bagi simpulan fenomena antara variabel bebas dan variabel tergantungnya, dalam hal ini penelitian ditujukan untuk mengetahui efektifitas program UPPKS di kecamatan Ciasem Kabupan Subang Jawa Barat.

Lokasi penelitian ini dilakukan di kecamatan Ciasem Kabupaten Subang Jawa Barat. Pengambilan (Simple Random Sampling) sampel acak sederhana adalah suatu cara pengambilan sampel dimana tiap unsur yang membentuk populasi diberi kesempatan yang sama untuk terpilih menjadi sampel. Sumber data dalam penelitian ini dengan mengumpulkan kuisioner sebanyak 120 responden. Obyek penelitian yang digunakan dalam penelitian ini adalah anggota masyarakat terutama ibu rumah tangga yang mengikuti program UPPKS di kecamatan Ciasem.

Pengujian instrumen penelitian menggunakan uji validitas dan uji reliabilitas dimana instrumen yang dipakai dalam penelitian akan dapat berfungsi baik apabila instrumen tersebut valid dan reliabel. Uji validitas dengan cara mengkolerasikan antar skor setiap instrumen dengan skor jumlah seluruh instrumen pernyataan. Syarat validitas harus memenuhi batas minimum yaitu $r=$ 0,3 . Butir pernyataan dalam penelitian harus memiliki koefisien kolerasi > 0,3 untuk memenuhi syarat validitas (Sudarmanto, 2005).

Menurut Husein (2004), reliabilitas adalah ukuran derajat ketepatan, ketelitian, dan keakuratan yang ditunjukkan oleh instrumen pengukuran denganpengujiannyadilakukan secara internal. Variabel dapat dikatakan reliabel jika nilai Cronbach Alpha > 0,6 (Ghozali, 2006:20). Efektivitas Program UPPKS yang dilaksanakan di Kecamatan Denpasar Barat diketahui dengan menggunakan teknik analisis data statistik deskriptif untuk menganalisis data dengan cara mendeskripsikan atau menggambarkan data yang telah terkumpul sebagaimana adanya tanpa bermaksud membuat kesimpulan yang berlaku untuk umum atau generalisasi (Sugiyono, 2006:206). Manfaat penelitian terhadap masyarakat yang mengikuti Program UPPKS ini dapat dihitung menggunakan Tes Mc Nemar dengan melihat nilai signifikasi perubahan (Siegel, 1994:90).

Uji McNemar diperkenalkan oleh seorang ahli psikologi bernama Quinn McNemar pada tahun 1947. Uji ini digunakan untuk penelitian yang membandingkan sebelum dan sesudah peristiwa/treatment dimana tiap objek digunakan sebagai pengontrol dirinya sendiri ( i.e. evaluating repeated measurements of the same objects using them as their own control). Uji dilakukan pada 2 kelompok sampel yang berhubungan, skala pengukurannya berjenis nominal (binary respon) dan untuk crosstabulasi $2 \times 2$.

Formula uji MacNemar sebagai berikut :

\section{Rumus McNemar}

Dimana :

$\mathrm{X}^{2}=$ Nilai khai-kuadrat hasil perhitungan

$\mathrm{A}=$ Objek yang menampilkan perubahan jawaban dari positif menjadi negatif $\mathrm{D}=$ Objek yang menampilkan perubaha jawaban dari negatif menjadi positif $2=$ konstanta 


\section{Hasil dsn Pembahasan}

\section{Gambaran Umum Daerah Penelitian}

Kondisi umum Batas Wilayah Utara : Kecamatan Blanakan, selatan : Kecamatan Cikaum, timur Kecamatan Sukasari, Barat : Kecamatan Patokbeusi. Topografi . Dataran rendah, Pertanian Ketinggian $10 \mathrm{~m} / \mathrm{dpl}$. Visi : Terwujudnya kecamatan Ciasem Sehat, Cerdas, Terampil, Aman dan Religius, dengan menjunjung tinggi budaya lokal berbasis Gotong Royong.

Misi kecamatan ciasem yang pertama adalah mewujudkan pelayanan publik yang optimal disemua tingkat. Kedua, mewujudkan kualitas yang berdaya saing, beriman dan bertaqwa. Ketiga, mewujudkan aspirasi dan prakarsa keuletan dengan ketangguhan, kemandirian dalam pemberdayaan masyarakat. Keempat, mewujudkan Kecamatan Ciasem sebagai daerah Agribisnis dan Industri yang berwawasan lingkungan . Lima Meningkatkan partisipasi masyarakat dalam pembangunan.

Kondisi Geografis Luas Wilayah Kecamatan 6.507.980 Ha Luas Wilayah Per Kelurahan/Desa Ciasem Girang 1.109,346 Ha Sukamandi Jaya $1.323,741$ Ha Ciasem Tengah 735,345 Ha Ciasem Baru 678,350 Ha Ciasem Hilir 818,000 Ha Dukuh 884,783 Ha Jatibaru 744,505 Ha Sukahaji 105,450 Ha Pinangsari $108,980 \mathrm{Ha} \mathrm{L}$

\section{Uji reliabilitas}

Uji reliabilitas digunakan untuk mengukur suatu kuesioner yang merupakan indikator dari variabel atau konstruk. Suatu kuesioner dikatakan reliabel atau handal jika jawaban responden terhadap pertanyaan adalah konsisten atau stabil dari waktu ke waktu.

Salah satu metode pengujian reliabilitas adalah dengan menggunakan metode Alpha-Cronbach. Standard yang digunakan dalam menentukan reliabel dan tidaknya suatu variabel penelitian umumnya adalah perbandingan antara nilai $\mathrm{r}$-hitung dengan $\mathrm{r}$-tabel pada taraf kepercayaan $95 \%$ atau tingkat signifikansi 5\%.Apabila dilakukan pengujian reliabilitas dengan metode Alpha-Cronbach, maka nilai r-hitung diwakili oleh nilai alpha. Menurut Santoso (2001, h.227), apabila cronbach's alpha hitung lebih besar dari pada r-tabel dan alpha hitung bernilai positif, maka suatu instrumen penelitian dapat disebut reliabel.

Setelah dilakukan analisa terhadap item dengan bantuan program SPSS ver.16.00 menggunakan analisis reliability, maka diperoleh skala variabel sebagai berikut:

Berdasarkan ketentuan jika nilai cornbach's alpha pada tabel realiability statistik sama dengan atau lebih besar dari 0.60 maka pertanyaan tersebut adalah reliable (dapat dihandalkan). Nilai reliabilitas yang diperoleh dengan model cronbach's alpha antara 0.731 sampai 0.905 maka pertanyaan-pertanyaan pada variabel yang diajukan yang diajukan tersebut sudah reliable (dapat dihandalkan)

\section{Efektifitas program UPPKS}

Setelah melakukan kunjungan ke lokasi dan mengadakan wawancara mendalam dengan pengurus serta diskusi dan pengambilan kuesioner di lokasi menunjukkan bahwa program UPPKS dapat berjalan dengan efektif di kecamatan ciasem kabupan subang Jawa barat, hal ini dapat di lihat dari sekitar 89 responden menyatakan bahwa mereka mengalami peningkatan pendapatan diatas UMR setelah mengikuti program UPPKS, meskipun masih terdapat juga beberapa responden yang belum mendapatkan perubahan setelah mengikuti program UPPKS . Hal ini karena UPPKS dalam praktiknya menjadi seperti kelompok simpan pinjam yang anggotanya masingmasing memiliki usaha sendiri sebagai unit bisnis perorangan. Usaha kelompok yang tadinya masih ada sudah berubah menjadi usaha perorangan. Walaupun demikian, kegiatan kelompok sifatnya situasional masih dapat ditemui atau hanya musiman saja.

Selain itu pelaksanaan program UPPKS merupakan usaha yang berguna untuk meningkatkan pendapatan masyarakat. Dana modal UPPKS digunakan untuk kegiatan agrobisnis, ternak, pengrajin, industri kecil (industri 
rumah tangga) pedagang pasar, pedagang kaki lima dan lain-lain.

Beberapa dari peserta program UPPKS memanfaatkannya untuk industry kecil rumah tangga yang produksinya dilakukan sendiri oleh anggota dengan keluarga sebagai usaha rumahan. Sehingga hal ini dapat berperan dalam meningkatkan pendapatan dan kesejahteraan keluarga dalam memenuhi kebutuhan sehari-hari, namun tabungan anggota untuk menambah modal diakui sulit karena keuntungan relatif kecil.

\section{Tes Mc Nemar}

Persepsi responden terhadap manfaat kepada penerima bantuan Program UPPKS dapat dilihat berdasarkan sisi pendapatan dan kesempatan kerja dengan menggunakan statistik non parametrik dengan Tes McNemar. Hasil dari persepsi responden terhadap manfaat Program UPPKS dilihat dari sisi pendapatan disajikan pada Tabel 3

Hasil Output SPSS di atas, nilai Chi-square sebesar 8.008 dan signifikansi p-value sebesar 0.005. Karena nilai sig.pvalue $0.000<0.05$ maka tolak hipotesis nol yang artinya ada perubahan yang signifikan pelaksanaan program UPPKS di kecamatan Ciasem sebelum dan sesudah pelaksanaan program dilakukan.

Berdasarkan hasil kuesioner yang di peroleh menunjukkan bahwa terdapat 89 responden mengikuti Program UPPKS, menyatakan bahwa mereka memiliki pendapatan dibawah UMR (1) dan mengalami perubahan setelah mengikuti Program UPPKS menjadi pendapatan diatas UMR (2). Hal ini sesuai dengan hasil penelitian yang dilakukan oleh (Heryendi,2013) yang menyatakan bahwa pelaksanaan Program UPPKS adalah sangat efektif, yaitu 86,56 persen responden menyatakan bahwa program ini dilaksanakan sesuai dengan harapan dan tujuan. Program serta Tes Mc Nemar menunjukkan terjadi perubahan tingkat kesejahteraan responden secara signifikan yaitu peningkatan pendapatan dan kesempatan kerja dilihat dari jam kerja responden pada saat sebelum dan sesudah mengikuti program UPPKS di Kecamatan Denpasar Barat.

Namun juga terdapat responden yang sebelum mengikuti Program UPPKS memiliki pendapatan dibawah UMR (1) dan tidak mengalami perubahan setelah mengikuti program UPPKS, melainkan memiliki pendapatan yang tetap dibawah UMR (2) sebanyak 17 orang dan sebaliknya ada responden yang sebelum mengikuti Program UPPKS memiliki pendapatan diatas UMR (2) dan tidak mengalami perubahan setelah mengikuti program UPPKS tetapi memiliki pendapatan yang tetap diatas UMR (1) sebanyak 11 orang. Hal ini sesuai dengan hasil (Simanjuntak, 2014) yang menyatakan bahwa usaha berkembang karena didukung oleh tambahan modal usaha yang diupayakan anggota sendiri dan juga karena pemilihan kegiatan usaha yang menguntungkan.

Pengurus dan anggota lebih menyukai bentuk pelatihan teknis, barang tertentu yang lebih laku. Usaha perorangan lebih banyak berdagang makanan dan minuman karena lebih cepat perputaran uangnya, selebihnya kerajinan tangan yang produknya belum tentu laku cepat, dan inilah keuntungan proses pembelajaran melalui UPPKS. Penelitian menunjukkan bahwa dampak bantuan Program UPPKS tersebut tidak ada hubungannya dengan penghasilan seseorang, kecuali melalui interaksi sosial dengan tetangga, teman sekolah, satu pekerjaan, dan sama-sama dalam institusi lainnya. Seseorang membuat pilihan untuk bekerjasama dengan orang yang berbeda suku, kelompok dan agama dan bisa cocok satu sama lain. Suatu teori baru didasarkan pada titik persimpangan konseptual antara teori pertukaran dan teori identitas (Brown, 2006). Walaupun kedua teori memiliki penekanan yang berbeda digunakan dalam topik-topik penelitian, kedua interaksi sosial tersebut mempelajari dan memahami 
banyak fenomena yang sama melalui kacamata yang berbeda.

\section{KESIMPULAN DAN SARAN}

\section{Kesimpulan}

a. Berdasarkan hasil analisis dan pembahasan di peroleh kesimpulan bahwa terdapat pelaksanaan program UPPKS di kecamatan Ciasem terbukti efektif dapat meningkatkan tingkat pendapatan dan kesejahteraan keluarga, hal ini karena peserta program memanfaatkannya sebagai modal untuk industry kecil, agroindustry dan peternakan.

b. Hasil Output SPSS di atas, nilai Chi-square sebesar 8.008 dan signifikansi p-value sebesar 0.005 . Karena nilai sig.p-value $0.000<$ 0.05 maka tolak hipotesis nol yang artinya ada perubahan yang signifikan pelaksanaan program UPPKS di kecamatan Ciasem sebelum dan sesudah pelaksanaan program dilakukan.

c. Berdasarkan hasil analisis dan pembahasan di peroleh kesimpulan

\section{Daftar pustaka}

Arifin, A. (2012). Nelayan Dalam Perangkap Kemiskinan (Studi Strukturasi Patron-Klien dan Perangkap Kemiskinan Pada Komunitas Nelayan di Desa Tamalate, Kec. Galesong Utara, Kabupaten Takalar, Provinsi Sulawesi Selatan).

Brown, LD. (2006). Memperkenalkan Teori Interaksi Sosial, Paper disajikan pada pertemuan tahunan American Association Sosiologi, Montreal Convention Center, Montreal, Quebec, Kanada

Elizabeth, R. (2007). Pemberdayaan Wanita mendukung Strategi Gender Mainstreaming dalam Kebijakan Pembangunan Pertanian bahwa terdapat perubahan yang signifikan pelaksanaan program UPPKS di kecamatan Ciasem sebelum dan sesudah pelaksanaan program dilakukan.

\section{Saran}

Berdasarkan kesimpulan di atas maka penulis akan memberikan beberapa saran yang diharapkan dapat menjadi masukan dan bahan pertimbangan antara lain :

a. Perlu diadakannya pengenalan lebih dalam lagi kepada masyarakat tentang kegiatan UPPKS

b. Masih terbatasnya akses penambahan modal sehingga hanya dapat digunakan untuk industry kecil dan industry rumahan, sehingga perlunya menghubungkan dengan penyedia pendaan lainnya ketikaa program sudah terbukti berjalan.

c. Perlunya perluasan pemasaran produk yang dihasilkan oleh peserta karena pemasaran untuk industry perorangan masih terbatas di lingkungan tempat tinggal masing-masing.

di Perdesaan. In Forum Penelitian Agroekonomi (Vol. 25, No. 2, pp. 126-135).

Ghozali, Imam. 2006. Aplikasi Analisis Multivariate dengan Program SPSS. Semarang: Badan Penerbit Universitas Diponegoro.

Heryendi, W. T. (2013). Efektivitas Program Usaha Peningkatan Pendapatan Keluarga Sejahtera (UPPKS) Di Kecamatan Denpasar Barat. Jurnal Ekonomi Kuantitatif Terapan, 6(2).

Husein, Umar. 2000. Metode Penelitian Untuk Sripsi dan Tesis Bisnis.Jakarta: 
Marhaeni, A. A. (2007). Evaluasi Kondisi Kelompok Usaha Peningkatan Pendapatan Keluarga Sejahtera (UPPKS) Di Kabupaten Karangasem.

Pakpahan, A. (1996). Penaggulangan Kemiskinan: Prinsip Dasar, Metodologi dan Upaya Penanggulangannya. Memahami dan menanggulangi kemiskinan di Indonesia: Prof. Dr. Sajogyo 70 tahun, 97.

Siegel, Sidney. 1994. Statistik Non Parametrik Untuk Ilmu-ilmu Sosial. Jakarta: PT. Gramedia.
Simanjuntak, M. (2014). Analisis Kelompok Usaha Peningkatan Pendapatan Keluarga Sejahtera di Dki Jakarta, 2014. Binus Business Review, 5(2), 601-614.

Sudarmanto, R.G. 2005. Analisis Regresi Linier Ganda dengan SPSS. Edisi Pertama.Yogyakarta: Graha Ilmu

Sugiyono. 2006. Metode Penelitian Bisnis. Bandung: Alfabeta. Suparlan, Parsudi. 1984. Kemiskinan Perkotaan. Jakarta. Sinar Harapan 